\title{
Cipo-César en las Metamorfosis de Ovidio: ¿una reivindicación de la monarquía?
}

\author{
Pablo Martínez Astorino \\ Universidad Nacional de La Plata / CONICET (Argentina) \\ pmastorino@gmail.com
}

El personaje de Cipo en las Metamorfosis de Ovidio ha sido analizado como una contraimagen de César ${ }^{1}$, de Augusto $^{2}$ o de ambos $^{3}$, o bien como una alusión irónica al princeps ${ }^{4}$. Más recientemente, se lo interpretó como una alusión a Rómulo y el carácter connatural a Roma de la monarquía ${ }^{5}$ o a Agripa y su renuncia a celebrar un triunfo que podía representar un desafío para el nuevo orden imperial ${ }^{6}$. Por su parte, Roland Granobs prefirió estu-

* Recebido em 02-12-2016; aceite para publicação em 03-07-2017.

** Versiones previas de este trabajo han sido presentadas desde fines de 2014 en tres reuniones científicas que han tenido lugar en la Argentina, con el auspicio de la Asociación Argentina de Estudios Clásicos. Agradezco los comentarios que me han hecho en la última (Morón, octubre de 2016) Alicia Schniebs (Universidad de Buenos Aires), Agustín Moreno (Universidad Nacional de Córdoba) y Federico Andrade Marambio (Universidad Nacional de La Plata), estos dos últimos historiadores dedicados respectivamente a la Antigüedad y el Renacimiento y la Modernidad. Agradezco asimismo las observaciones de uno de los evaluadores, que me permitieron acentuar en la revisión las apreciaciones originales - no desarrolladas por otros críticos, según mi compulsa - de este artículo. Se ha empleado el texto de R. J. TARRANT (P. Ovidi Nasonis Metamorphoses, Oxford, 2004) para las citas de Metamorfosis y el de E. H. Alton, D. E. W. Wormell, E. Courtney (P. Ovidi Nasonis Fastorum Libri Sex, Leipzig, 1988) para las citas de los Fastos.

1 D. Porte, "L'idée romaine et la métamorphose", in J-M. Frécaut, D. Porte (edd.), Journées ovidiennes de Parménie: actes du Colloque sur Ovide, 24-26 juin 1983, Bruxelles, 1985, p. 195.

2 S. Lundström, Ovids Metamorphosen und die Politik des Kaisers, Upsala, 1980, pp. 67-79; U. SchmitZer, Zeitgeschichte in Ovids Metamorphosen. Mythologische Dichtung unter politischem Anspruch, Stuttgart, 1990, pp. 260 ss.

3 S. WHEELER, Narrative Dynamics in Ovid's Metamorphoses, Tübingen, 2000, p. 130.

${ }^{4}$ K. GalinsKY, "The Cipus Episode in Ovid's Metamorphoses (15, 565-621)", TAPhA, 98, 1967, 181-191. A. BARCHIESI, Il poeta e il principe. Ovidio e il discorso augusteo, Roma/ Bari, 1994, p. 252. A diferencia de Barchiesi, que descubre una alusión al imperialismo de Augusto en la aceptación de las tierras por parte de Cipo, Galinsky no ve en la ironía de Ovidio propósitos políticos, sino falta de compromiso con la ideología augustea.

${ }^{5}$ R. MARKs, "Of Kings, Crowns, and Boundary Stones: Cipus and the hasta Romuli in Metamorphoses 15", TAPhA, 134, 2004, 127-128.

${ }^{6}$ F. Díez Platas, P. López Barja de Quiroga, "Cipo en las Metamorfosis de Ovidio y en su recepción posterior”, in C. Fornis, J. Gallego, P. López Barja, M. Valdés (edd.), Dialéctica histórica y compromiso social. Homenaje a Domingo Plácido, Zaragoza, 2010, pp. 278 ss. 
diarlo omitiendo sus posibles alusiones a la historia romana del período cesáreo-augusteo ${ }^{7}$.

Nuestro trabajo, enmarcado en una investigación sobre la representación de la historia en las Metamorfosis de Ovidio con proyección en otros autores augusteos, postula que, antes que con fines políticos, el episodio debe entenderse en términos literarios como una mitologización del personaje de César previa a su apoteosis, de igual modo que el episodio de Esculapio, según hemos intentado demostrar en un artículo reciente ${ }^{8}$, constituye una mitologización del personaje de Augusto. Como en el caso del princeps, el fin es aludir de manera mitologizada a dos episodios de la vida política de César: el rechazo de las insignias reales en primer lugar de parte del Senado y, luego, de Antonio el día de las Lupercales (Iul. 79.2); pero, aunque lo más medular de esta representación de la historia sea el artificio per se, hay lugar, como veremos, para una reflexión sobre la monarquía en la historia de Roma, que opera como significativa interpretación de la historia reciente.

\section{El episodio de Cipo como "mitologización”: por qué César}

El episodio de Cipo no aparece relatado antes de Ovidio y los críticos se preguntan cuáles han sido las posibles fuentes y cuán conocido era entre los romanos cultos. Lo que queda son dos referencias posteriores a Ovidio, la última de las cuales, debida a Valerio Máximo (5.6.3), es la más valiosa por su longitud. La referencia de Plinio el Viejo (Nat. Hist. 11.123) resulta de especial importancia para nuestra hipótesis y la trataremos más adelante ${ }^{9}$. No obstante, fuera del pasaje ovidiano, el relato más conocido es éste de Valerio Máximo (5.6.3), que se inserta en una serie de exempla iniciados en 5.4 de pietate erga parentes et fratres et patriam ${ }^{10}$ :

Genucio Cipo praetori paludato portam egredienti noui atque inauditi generis prodigium incidit: namque in capite eius subito ueluti cornua erepserunt, responsumque est regem eum fore, si in urbem reuertisset. quod ne accideret, uoluntarium ac perpetuum sibimet indixit exilium. dignam pietatem, quae, quod ad solidam gloriam attinet, septem regibus praeferatur. cuius testandae gratia capitis effigies aerea portae, qua excesserat, inclusa est dictaque Rauduscula: nam olim aera raudera dicebantur.

${ }^{7}$ R. GRANOBS, Studien zur Darstellung römischer Geschichte in Ovids 'Metamorphosen', Frankfurt, 1997, pp. 134 ss.

8 P. MARTÍNEZ ASTORINO, "Intratexto, mitologización y construcción poética de la historia en el episodio de Esculapio (Ovidio, Metamorfosis 15.622-744)", in L. Galán, M. D. Buisel (edd.), La adivinación en Roma. Oráculos, vaticinios, revelaciones y presagios en la literatura romana (2013), La Plata, 2015, pp. 145-160.

9 Como afirma P. Hardie, Ovidio. Metamorfosi, Volume VI (libri XIII-XV), Milano, 2015, ad Met. 15.565-621, "La storia (...) probabilmente ebbe origine come aïtıv per un'apotropaica testa cornuta di bronzo che si trovava presso la porta".

10 J.-Y. Guillaumin, "Les cornes de Cipus", in F. Galtier, Y. Perrin (edd.), Ars pictoris, ars scriptoris. Peinture, littérature, histoire. Mélanges offerts à Jean-Michel Croisille, ClermontFerrand, 2008, p. 165. 
"A Genucio Cipo, pretor vestido con el manto guerrero, al traspasar la puerta le ocurrió un prodigio de tipo nuevo e inaudito: pues de repente en su cabeza le salieron como unos cuernos y se le respondió que, si volvía a la ciudad, sería rey. Para que no sucediera esto, se impuso a sí mismo un exilio voluntario y perpetuo. ¡Digna muestra de piedad, que, en lo que atañe a la sólida gloria, debería anteponerse a los siete reyes! Para dejar testimonio de ésta, fue incrustada en la puerta por donde había salido una imagen de bronce de su cabeza y la puerta fue llamada raudusculana, pues antiguamente los bronces - aera eran llamados raudera."

Como se ha señalado, hay diferencias considerables entre este relato y el de Ovidio, que involucran variados aspectos ${ }^{11}$. Mientras que Valerio Máximo refiere el nomen (Genucius) y el cognomen (Cipus) del personaje y nos informa sobre el cargo que desempeñaba (praetor), Ovidio sólo lo llama por su cognomen (v. 565). En Ovidio, Cipo regresa triunfante de una batalla (ut uictor domito veniebat ab hoste, v. 569), en tanto que Valerio lo muestra saliendo al campo de batalla con vestimenta militar (paludatus). En cuanto al lugar, el Cipo valeriano sale por la porta Rauduscula y, a propósito de ella, el autor registra una etimología; en Ovidio el sitio en el que se desarrolla la asamblea de Cipo con el pueblo y el Senado es un tanto ambiguo, pero no hay base textual para afirmar que ocurre dentro de la ciudad, como opina Galinsky, y sí para sostener su ubicación fuera de la ciudad ${ }^{12}$. El monumento que celebrará la hazaña (y el prodigio de los cuernos) de Cipo será también diverso en cada caso: en Valerio, una cabeza de bronce en la puerta raudusculana $^{13}$; en Ovidio, unos cuernos de bronce. Para explicar el prodigio de la aparición de cuernos en la cabeza de Cipo, el relato de Ovidio apela a la religión (hay un arúspice, sacrificios y un altar), que se encuentra del todo ausente en Valerio: su lacónico responsum est indica meramente que hubo una consulta del Senado. Por último, la consecuencia del episodio es también diversa en cada autor. El Cipo de Valerio se impone un exilio voluntario, mientras que el de Ovidio obra de una manera que ha despertado suspicacias: se tapa sus cuernos y pide al pueblo que alejen de la ciudad y maten si es necesario a quien, porque lleva cuernos, será rey, y luego se muestra ante todos (vv. 594 ss.); se le otorga entonces un campo para arar en las afueras de la ciudad.

Dos motivos que aparecen en el relato de Ovidio han sido especialmente considerados por la crítica: el regreso triunfal de Cipo y la corona de laurel con la que cubre sus cuernos, motivo que continúa en la coronación de Cipo, por parte del pueblo, con una corona festa (v. 615), que, como correspondía

11 Aunque esta enumeración puede elaborarse luego de una lectura atenta, hemos considerado y seguido en gran medida el cuadro de F. Díez Platas, P. López BARJa de Quiroga, art. cit., p. 281.

12 A S. WheELER (op. cit., p. 129, n. 98) se debe la observación sobre la invalidez de la tesis de Galinsky. A favor de la tesis contraria, U. Schmitzer (op. cit. pp. 264-265) y R. GRANOBS (op. cit., p. 137), que señala como decisivo los vv. 592 ss.: et aggeribus factis a milite forti/ insistit.

13 La explicación etimológica remite a Varrón, LL 5.63: Deinde Rauduscula, quod aerata fuit: aes raudus dictum ("luego viene la puerta raudúscula, pues era de bronce: bronce se decía raudus"). 
a los triunfos, era también de laurel. Pese a que Hermann Fränkel ${ }^{14}$, en su famoso libro, vinculó la corona de laurel y, en particular, la coronación final de Cipo con el rechazo de César a recibir las insignias reales (Suet. Iul. 79.2), i.e., la diadema de los reyes helenísticos, la crítica posterior, salvo excepciones, ha encontrado motivos para sostener una relación más estrecha con Augusto. Galinsky recuerda que quien estaba particularmente asociado al laurel apolíneo era Augusto: las puertas de su casa en el Palatino, por decreto del Senado, estaban flanqueadas por plantas de laurel, hecho que Ovidio cita repetidamente en su obra (especialmente en Met. 1.562-563), y el templo de Apolo se hallaba cerca de la casa de Augusto ${ }^{15}$. César, según registra Suetonio, usaba una corona de laurel (Iul. 45.2) y rechazó las insignias reales, pero al parecer usó también la corona aurea de los reyes etruscos en los últimos meses de su vida, hecho que podría invalidar su relación con $\mathrm{Cipo}^{16}$. Por otro lado, la corona triunfal que recibe Cipo en el relato de Ovidio ha sido asociada a dos triunfos celebrados por Augusto: el de Accio, en el 29 a.C. y la restitutio rei publicae del 23 a.C. ${ }^{17}$. A diferencia de Galinsky, que opina que Ovidio no se toma en serio la identificación, los críticos que ponen el acento en esta escena triunfal postulan que hay una aguda ironía y que Cipo es un anti-Augusto, pues en efecto hizo lo que Augusto no habría hecho: defender la república ${ }^{18}$. Por lo demás, su nombre se vincula con el sustantivo cippus, que significa "piedra de límite" y puede leerse de manera crítica en clave augustea.

Es difícil aceptar o descartar la validez de estas resonancias sin descubrir antes un conjunto de elementos que sirvan de base a la interpretación. Quisiéramos desplazar la atención, para ese fin, a un problema de composición del texto, que precisará de algunas aclaraciones. Postulamos, en efecto - y volvemos así a la idea de Fränkel -, que el pasaje debería ser leído en relación con César porque hay sustento para afirmar que el episodio posterior de Esculapio alude de manera bastante explícita al personaje de Augusto, y la obra culmina con la apoteosis de ambos líderes romanos, lo que diseñaría

14 H. FränKel, Ovid. A Poet between Two Worlds, Berkeley/ Los Ángeles, 1945, p. 226, n. 104.

15 K. GaLINSKY, loc. cit., 187.

16 K. GalinsKy, loc. cit., 186. Galinsky (n. 13) dice que esta conclusión proviene de lo que puede apreciarse en fuentes numismáticas. Véase bibliografía allí citada.

17 S. LunDSTRÖm (op. cit., p. 78) defiende el primero y U. SCHMitZer (op. cit., pp. 263 ss.), el segundo. Aunque en absoluto desdeñable, nos parece un tanto lateral, en relación con la trama de la obra, la hipótesis de F. Díez Platas, P. López Barja De Quiroga (art. cit., pp. 283 ss.), quienes sugieren que el rechazo de Cipo es una alusión a un episodio triunfal que involucra a Agripa. Éste, según cuenta Dión Casio (48.49.4; 54.12.1-2; 54.24.8), en el 37 a.C. (y luego en dos ocasiones más), rechazó celebrar un triunfo luego de su victoria en las Galias para no ofender la dignidad imperial, pues Augusto, mediante un portento, se había apropiado del laurel triumphalis.

18 Un buen resumen en S. LunDSTRÖM, op. cit., p. 79: "Ovids Erzählung von der Tat des Cipus hat uns also zum Triumph Octavians geführt. Das ist kein Zufall. Der Dichter hat allem Anscheim nach die Darstellung so geschaltet, dass seine Leser immer wieder an den Gegenstaz zwischen dem republikanischen Helden Cipus und dem triumphierenden Despoten Augustus denken mussten". 
una estructura en la cual las historias de Cipo y Esculapio obran como una anticipación (y a la vez como complemento argumental) con cierto grado mítico de los personajes de César y Augusto ${ }^{19}$. Se trata de una alusión y no de una alegoría, como parecen sugerir algunos críticos. Cipo y Esculapio siguen siendo Cipo y Esculapio, pero ingresan en un uso especial de la "mitologización" de Ovidio, artificio que, en términos generales, puede definirse como la asimilación del tono y el contenido de la parte histórica de la

19 Resumimos los elementos que unen a Esculapio con Augusto, conforme hemos estudiado en P. MARTínez Astorino (art. cit., pp. 152-154, 149-150). El oráculo de Apolo advierte que es Esculapio el dios al que los romanos deben dirigirse: nec Apolline uobis/ qui minuat luctus, opus est, sed Apolline nato./ ite bonis auibus prolemque accersite nostram ("no tenéis necesidad de Apolo para que calme vuestro dolor, sino del hijo de Apolo. Id con buen augurio y haced venir a mi descendencia”, 15.638-640). Si bien natus es por sí solo un término con el cual se designa a Augusto más adelante para destacar la relación con su padre adoptivo (15.819), natus Apolline alude a la creencia de que Augusto era el fruto de la unión de Acia y Apolo en forma de serpiente: Augustum natum mense decimo et ob hoc Apollinis filium existimatum (Aug. 94.4). La relación con Apolo se ve especialmente acentuada en los versos siguientes, en los que se llama a Esculapio, de manera acorde con Augusto, iuuenis Phoebeius (v. 642). Una segunda afinidad entre Esculapio y Augusto se halla en la expresión salutifer urbi/ orbi, que puede aplicarse tanto a Esculapio como a Augusto en tanto salvadores de la ciudad y, según la visión romana, del mundo, y en tanto hijos que suceden a sus padres (cf. S. WHEELER, op. cit., p. 138). Igualmente, el fin del viaje de Esculapio es salvar a Roma de una dira lues (15.626), mientras que la dira lues de la que salvará Augusto al pueblo de Roma - recuérdese que la metáfora de la enfermedad se ha empleado desde antiguo para referirse a la guerra (cf. U. SCHMITZER, op. cit., p. 276) - será la guerra civil, mencionada por el poeta pocos versos después (15.826828). Por último, la vinculación entre Esculapio y Augusto en términos de "mitologización" (véase más adelante en el cuerpo del artículo) permite comprender mejor el final de la plegaria a Augusto con la palabra absens (Met. 15.868-870). Aunque el absens podría entenderse, si lo comparamos con la exclamación final del poeta (uiuam, v. 879), como una cuestión de énfasis (es el poeta quien tiene la última palabra y su apoteosis, en tanto más elevada - super alta.../ astra, 15.875-876 -, se define como superior a la del princeps), si aceptamos la idea de "mitologización" como clave para interpretar este episodio, el praesens del v. 646 (Graiosque patres... darentquel orauere deum qui praesens funera gentis/ finiat Ausoniae - "rogaron a los padres griegos que les entregaran al dios para que con su presencia pusiera fin a las muertes de Ausonia”, 15.645-647), que evoca la ayuda pedida por la embajada que va en busca de Esculapio, debería encontrar algún eco en los versos dedicados a Augusto. No obstante, el hecho de que haya un Augusto praesens es también un requisito formal de una obra en la que la elevación del poeta sólo adquiere pleno sentido si se compara con otras elevaciones como la de César, la de Augusto y aun la de Pitágoras en una estructura de priamel (cf. L. B. WiCKKISER, "Famous Last Words: Putting Ovid's Sphragis Back into the Metamorphoses", MD, 42, 1999, 134-139). Es así que, aun cuando se consigne la palabra absens, el praesens del episodio de Esculapio, definido como un término medio entre su presencia y su ayuda como dios, encuentra su eco en un Augusto cuya obra salvífica se manifiesta en su carácter de praeses rerum (v. 758). Si bien la raíz de la expresión, pese a la afinidad sonora, no es la misma, es en el "presidir" que se hace efectivo el carácter salvífico que Augusto comparte con Esculapio y es esto mismo lo que, formalmente, define en los hechos su praesentia benefactora del género humano. En cuanto a la conversión de Esculapio en una serpiente, antes que entenderlo negativamente, debe considerarse que remite a significativos episodios de las Metamorfosis en que el motivo de la serpiente posee un importante valor: el pasaje final de Cadmo y Harmonía (4.600-603) y la apoteosis de Hércules (9.266-269). Hacia el final de las Metamorfosis, el dios-serpiente recuerda que las anteriores apariciones del motivo en contextos de apoteosis (Hércules) o elevación (Cadmo y Harmonía) actúan como prefiguraciones, por lo que se exige un esfuerzo interpretativo para trascender los posibles rasgos humorísticos de los pasajes en que el motivo aparece. 
obra al tono y el contenido de los relatos griegos de la parte mítica ${ }^{20}$. Con todo, un uso especial de la "mitologización". En el pasaje de César o en la "Eneida" ovidiana eran, entre otras cosas, el marco de la Eneida o las historias de la Odisea respectivamente las que conferían al relato histórico un tono mítico ${ }^{21}$. En el episodio de Esculapio es en especial la alusión del viaje de Esculapio al de Augusto, un personaje histórico, lo que permite la mitologización del viaje de Augusto. Augusto, a diferencia de César o de Eneas, no se encuentra en el interior de la representación, sino que está aludido. En el episodio de Cipo, César, que está aludido, se encuentra también fuera de la representación.

Ahora bien, ¿es lícito caracterizar como mitologización un episodio que Ovidio parece haber tomado de la historia? Plinio el Viejo nos ayuda a convencernos de que lo es. En efecto, este autor, aludiendo a Met. 3.131-252, el episodio de Acteón, equipara los cuernos de Cipo a los de Acteón y concluye: Actaeonem ... et Cipum etiam in Latia historia fabulosos reor ("A Acteón y aun a Cipo en la historia romana juzgo fabulosos"). Es acertado postular, creemos, que a través de Cipo Ovidio construye la mitologización de un personaje histórico porque su historia es una historia republicana que los propios romanos veían como cuasimítica; de hecho el término empleado por Plinio (fabulosos) remite a una designación religiosa que nos ha transmitido Varrón: la theologia fabulosa, i.e., el mito. Ese carácter mítico se refuerza por el valor intratextual que adquiere en las Metamorfosis no sólo en relación con los cuernos de Acteón, sino con los de Ío (1.640-641) y Acis (13.894)22, personajes míticos de la obra ${ }^{23}$.

Quedaría encontrar en el texto elementos adicionales que confirmaran la relación de Cipo con César. Aunque es un trabajo en el que se podría ahondar en una ulterior investigación, luego de tratar la derivación final de la mitologización operada en este pasaje, propondremos un elemento.

\section{¿Resignación a la monarquía o reivindicación de la monarquía?}

Es importante recordar, como lo han hecho algunos críticos, en especial Marks ${ }^{24}$, que el episodio de Cipo se inserta en un pasaje que comienza con la referencia al arúspice Tages y el hasta Romuli (cf. 561). Como afirma Galinsky, "The brief reference of the hasta Romuli (15.560-564) serves to recall the Romulus story of Book 14 and appropriately associates the first

${ }^{20}$ Hemos estudiado este tema en P. Martínez Astorino, La apoteosis en las Metamorfosis de Ovidio: función estructural y valor semántico, Tesis doctoral, La Plata, 2009, pp. 66 ss.; passim.

${ }^{21}$ Para la "mitologización" en esos pasajes, véase P. MARTínez Astorino, op. cit., pp. 135 ss., 206 ss.

22 S. WheEler, op cit., p. 128; D. PorTe, op. cit., p. 194.

23 J.-Y. Guillaumin (art. cit., pp. 166-167) insiste en el humor que los paralelos entre Cipo y Acteón sugieren, pero sin restar importancia al sentido político en el caso de Cipo. Creemos que la mitologización es un aspecto más básico para la interpretación que el humor.

${ }^{24}$ R. MARKS, loc. cit. 
Roman rex with the king-in-spite-of-himself, Cipus"25. La pregunta que surge es: ¿esa alusión a Rómulo - y, por tanto, al problemático estatus de la monarquía en la historia romana - obra en el texto como una crítica indirecta a César o a Augusto, a través de Cipo, o más bien la aparición del primer rey en esta historia republicana sugiere una asociación con la monarquía, la consideración de la monarquía como un legado inevitable entre los romanos? Las apreciaciones de Marks sobre el punto son elocuentes: "If Augustus had made Cipus' choice, the issue of kingship, so Ovid suggests, would not have been resolved anyway; it simply would have been postponed for another day, for another Cipus or another Augustus (u otro César)"26. Nosotros proponemos ir más allá y preguntarnos si, pese a las reformulaciones de la crítica (en especial, de Habinek ${ }^{27}$ ), no seguimos leyendo demasiado republicanamente a Ovidio, sin considerar su obra con más atención. Uno de los personajes políticos que más aparecen elogiados en las Metamorfosis y en los Fastos de Ovidio es Numa, que es un rey y no un personaje de la república romana. Puede decirse que, sobre todo en los Fastos, Ovidio procura tejer algún tipo de relación especial entre Numa y Augusto, si bien podría haber optado por realzar, observando el valor de exemplum que suele adquirir la historia romana ${ }^{28}$, la presencia de personajes republicanos en estas dos obras, como lo hizo Virgilio, por ejemplo, en los libros 6 y 8 de la Eneida. No lo hizo y hay, posiblemente entre otros, un motivo que es de orden personal y estético. Como lo expresa en el Ars Amatoria (3.121 ss.) ${ }^{29}$, Ovidio no considera que los tiempos antiguos sean una edad dorada, sino una época rústica, y en algunas ocasiones, cuando mira al pasado, mira a Grecia, como en ese pasaje de los Fastos (3.101 ss.), que es una respuesta al famoso pasaje de Virgilio sobre las artes Romanae:

nondum tradiderat uictas uictoribus artes
Graecia, facundum sed male forte genus:
qui bene pugnabat, Romanam nouerat artem:
mittere qui poterat pila, disertus erat.

"Grecia todavía no había legado las artes vencidas

a los vencedores; era un pueblo elocuente, pero poco valiente.

Quien luchaba bien conocía el arte romana; quien podía arrojar dardos era elocuente..."

25 K. GaLinsKy, loc. cit., 183.

26 R. MARKS, loc. cit., 128.

27 T. HabineK, "Ovid and Empire", in P. Hardie (ed.), The Cambridge Companion to Ovid, Cambridge, 2002, pp. 46-61.

28 H. ARENDT, "El concepto de historia: antiguo y moderno", in H. Arendt, Entre el pasado y el futuro. Ocho ejercicios sobre la reflexión política (trad. A. Poljak), Barcelona/ Buenos Aires, 2016, p. 107: "Para un cristiano, como para un romano, la significación de los acontecimientos seculares estriba en que tengan el carácter de ejemplos que se puedan repetir, de modo que la acción puede seguir ciertos ejemplos normalizados. (Esto, incidentalmente, está también muy alejado de la idea griega de proeza, relatada por poetas e historiadores, que sirve como una especie de patrón para medir las capacidades de grandeza propias)".

29 Prisca iuvent alios, ego me nunc denique natum/ gratulor: haec aetas moribus apta meis ("Que a otros agraden las cosas antiguas; yo me alegro de haber nacido ahora. Esta edad es adecuada a mis costumbres”). 
Aunque en ambos pasajes Ovidio se refiera a la época monárquica, el nondum... Graecia nos transporta al período anterior al comienzo del influjo helenístico en la sociedad romana, que supone varios siglos caracterizados de diversos modos por algunos escritores romanos, incluyendo al propio Tibulo, como una idealizada edad de oro. La nómina de los escritores excluye a Ovidio. El primer pasaje demuestra la preferencia de Ovidio por el presente y no por los tiempos antiguos, de manera general; en el segundo los tiempos antiguos incluyen en su desprecio la república idealizada. Si se considera que en Fastos y Metamorfosis Ovidio ha representado de manera especialmente celebratoria la monarquía de Numa, puede deducirse que los tiempos claramente desdeñados son los de la antigua república.

Este marco sirve para entender algunos puntos oscuros y controvertidos del episodio de Cipo, que citaremos a continuación. Cuando Cipo consulta al arúspice, éste le contesta (vv. 581 ss.):

'rex' ait, 'o salue! tibi enim, tibi, Cipe, tuisque

hic locus et Latiae parebunt cornibus arces.

tu modo rumpe moras portasque intrare patentes adpropera; sic fata iubent. namque urbe receptus rex eris et sceptro tutus potiere perenni'.

“'salve, rey', dijo. 'Pues a ti, Cipo, a ti y a tus cuernos este lugar y las fortalezas latinas obedecerán.

Tu sólo depón toda tardanza y apresúrate a entrar en las puertas abiertas. Así lo ordenan los hados. Pues recibido en la ciudad, serás rey y te apoderarás/ gozarás seguro de un cetro duradero."

Ése es el omen y en él no hay ninguna nota negativa. De hecho, son los hados quienes ordenan su cumplimiento: con rumpe moras se alude a la aparición de Mercurio a Eneas para recordarle su fatum en el libro 4 de la Eneida (v. 569), una obra que tiene al fatum como motivo central ${ }^{30}$. Cipo se resiste a cumplirlo y afirma (v. 587 ss.):

\author{
procul, a! procul omina' dixit \\ 'talia di pellant! multoque ego iustius aeuum \\ exul agam quam me uideant Capitolia regem'. \\ “'ique los dioses empujen lejos, ay, tales augurios' \\ dijo 'y sería mucho más justo que yo pase la vida como un exiliado \\ antes que el Capitolio me vea como rey'."
}

30 Cf. F. Bömer, P. Ovidius Naso, Metamorphosen. Kommentar (XIV-XV), Heidelberg, 1986, ad loc. La alusión al ingreso del caballo en Troya de Eneida 2.34, sic fata ferebant, que señala Guillaumin (art. cit., 2008, p. 170), con conclusiones negativas respecto del carácter inexorable de la monarquía, no parece muy determinante en este contexto. Tampoco puede afirmarse, como afirma P. HARDIE, op. cit., ad Met. 15.583-585, que, a diferencia de Eneas, Cipo observará la pietas no siguiendo el fatum. La alusión a los hados de la Eneida, que está resaltada por la evocación, parece adquirir, más bien, un sentido general y positivo y Cipo, al desobedecer los hados, está infringiendo la voluntad de los dioses. 
Esa convicción republicana que evidencia Cipo gozaba de tanto prestigio en Roma que se observa aun en el rechazo de César, un hombre que ya no creía en la república. En este sentido, no es para nada extraño que Ovidio haya querido aludir a él con este episodio. La crítica se ha sorprendido de la estratagema posterior de Cipo: cubre sus cuernos y convoca al pueblo y al Senado ${ }^{31}$, frente a los cuales exclama (vv. 594-595): 'est' ait 'hic unus, quem uos nisi pellitis urbe,/ rex erit ("hay uno, dijo, que si vosotros no lo expulsáis de la ciudad, será rey"). En lugar de mostrar los cuernos, Cipo los esconde. Ese acto, creemos, responde a dos posibles sentidos, no excluyentes: por un lado sirve para probar si el pueblo es capaz de rechazar la monarquía en abstracto (si supieran que él es el rey, la aceptarían); por el otro, Cipo, en cierto modo, juega con la posibilidad de que el pueblo acepte la monarquía y lo aclame, pero no se atreve a esto, por lo que el deseo queda a medio camino, y explica que ese rey los someterá a la esclavitud (quem... famularia iura daturum - "éste os dará leyes de esclavos", vv. 596-597) y que es, en realidad, un tyrannus (v. 601), algo que no estaba en el augurio ${ }^{32}$.

En conclusión, Cipo no se atreve a ser rey. El texto de Ovidio dice sugestivamente con una construcción personal (v. 616) quoniam muros intrare uetaris ("ya que tú eres prohibido penetrar los muros") y el lector se pregunta si en rigor el agente de la prohibición no es él mismo, que no puede apoderarse o, más bien, gozar, conforme a la doble semántica del verbo (potiri, cf. v. 585), del cetro. Cipo obra como el propio César, quien, aun habiendo hecho temblar los cimientos de la república, por alguna razón no se atrevió, en aquellas dos oportunidades famosas de coronación, a aceptar la diadema. En cuanto a Cipo, el pueblo, no obstante, lo corona con una corona festiva. Sin embargo, el final del episodio da lugar a conjeturar que ese legado monárquico no es del todo censurado y aun permanecerá. Éste es el elemento adicional que podría constituir una confirmación de que Cipo alude a César: los cuernos de Cipo son aquello que lo distingue como rey (is qui sit signo, non nomine, dicam;/ cornua fronte gerit - "diré por un signo, no por su nombre quién es: lleva cuernos en su frente", vv. 595-596) y aluden a la corona aurea de los reyes romanos (Dion. Hal. 3.61.1), que al parecer César usó. Son un testimonio de su carácter real y del carácter real que, pese a su rechazo, César habría adoptado fallidamente ${ }^{33}$. En el final del episodio

31 M. Haupt, R. Ehwald (Die Metamorphosen von P. Ovidius Naso VIII-XV, Berlin, 1916³) y P. HARDIE (op. cit.) ad loc. observan que, en este pasaje, Ovidio no es fiel a la tradición, ya que, aunque existen precedentes de comitia del pueblo o reuniones del Senado extra pomerium, no podrían haber sido convocados juntos, porque el pueblo se reúne sub divo y el Senado en un lugar cerrado. Indudablemente Ovidio no pretendió observar el marco legal, sino representar la escena con la mayor vivacidad - y a la vez representatividad - posible.

32 Creemos, por ende, que es insuficiente la conclusión de J.-Y. Guillaumin (art. cit., p. 170): "En contraste avec Valère-Maxime, Ovide, en effet, ne souligne pas la pietas du personnage, mais ses aspirations royales et ses insignia, qu'il essaie d'abord de dissimuler sous une couronne de laurier".

33 Lo que en la evocación y en la asociación de Cipo con César pueda suponer una crítica a César debería entenderse en forma comparativa como un énfasis, en la medida en que, más allá de la sinceridad de la representación, la plenitud de César parece encontrarse en Augusto: cf. Met. 15.746-759. 
de Cipo se dice, con participio futuro activo indicando destino ${ }^{34}$, que esos cuernos, esa corona, longum mansura per aeuum ("permanecerán a través de la larga edad", v. 621) 35 .

\section{Conclusiones}

En términos de representación de la historia puede decirse que Ovidio ha puesto el acento en un artificio (la alusión a César a través de Cipo), pero de alguna manera su vinculación constituye una interpretación sobre la época y sobre el principado (y no se trata de una interpretación marginal) ${ }^{36}$. El legado monárquico no se ve como una falta y no es un error ${ }^{37}$; es una opción viable, pero, conforme a lo que sugiere el relato de Ovidio, es preciso atreverse a tomarla ${ }^{38}$. Nunca podría ser un error porque no sólo Tarquino fue rey, sino Numa, cuya representación tanto en Metamorfosis como en Fastos es celebratoria.

En el caso de Numa y de Augusto, expresamente vinculados en Metamorfosis, ese legado puede servir para imponer la paz (15.483 ss. - Numa;

34 Cf. Bömer, op. cit., ad loc.

35 Como afirma J.-Y. Guillaumin (art. cit., p. 170), los cuernos pueden remitir a un poder de tipo helenístico: "Les cornes figurent en effet dans la panoplie de symboles dont disposent les rois hellénistiques pour orner leur portrait sur les émissions monétaires. Elles remontent à des portraits d'Alexandre présents sur des monnaies de ses successeurs: coiffé d'un casque orné de cornes et d'oreilles de taureau, avec autour du cou une peau de panthère, allusions dionysiaques, au droit de tétradrachmes de Séleucus, frappés à Persepolis vers 300; ou bien la tête ornée des cornes du bélier Ammon, sur des monnaies de Lysimaque, roi de Thrace, au début du III" siècle".

36 Para una discusión más precisa sobre esta terminología específica, remitimos a P. Martínez Astorino, "Representaciones de la historia republicana y reciente: Marcelo en Virgilio y Propercio", Maia, 66, 2014, 349-351.

37 El propio Cicerón, un defensor de la república romana, afirma en boca de Escipión la preferencia por la monarquía en el libro 1 de la República (vv. 54-63). Cicerón, sobreponiéndose a las posibles objeciones a esta forma de gobierno por parte de los nobles o el pueblo, opta por el sustento mítico-religioso, histórico y filosófico: 1) Júpiter gobierna a los dioses como un rey; 2) como otros pueblos antiguos, los romanos, que no fueron bárbaros, tuvieron al principio reyes; 3 ) así como para las almas es mejor someterse al mando (reinado - sub regno, v. 60) de la virtud de la prudencia (consilium, cf. v. 60), a los hombres les cuadra el gobierno de un rey, que se revela como particularmente necesario en situaciones de gravedad, como en caso de guerra. Agradecemos los comentarios de Alicia Schniebs. Cf. asimismo E. Dench, "Cicero and Roman Identity", in C. Steel (ed.), The Cambridge Companion to Cicero, Cambridge, 2013, p. 136: "When pushed to choose between 'simple' constitutional forms rather than selecting the complexity of the 'mixed constitution', 'Scipio' expresses his preference for monarchy (Rep. 1.35, 54-55). This choice is by no means incidental: the virtues of kings during Rome's regal period anticipate the rector in Books 5 and 6, the idealized statesman who acts in the best interests of the res publica"; y J. E. G. Zetzel, "Political Philosophy", in C. Steel (ed.), op. cit., p. 186: "Monarchy is the best simple form not merely because an executive of some kind is the one essential element in all government, and not merely - although it is important - because Rome began as a monarchy, but because Cicero constantly chooses to emphasize the role of individuals in government".

${ }^{38}$ La opinión de Valerio Máximo (5.6.3) no es en absoluto ambigua (dignam pietatem, quae, quod ad solidam gloriam attinet, septem regibus praeferatur), lo que destaca la riqueza del texto ovidiano. 
15.822 ss., 832 ss. - Augusto), las leyes y la religión, aun cuando en el caso de Augusto sea, en gran medida, a través de la guerra (cf. pacificación) ${ }^{39} \mathrm{o}$, según la versión contrafáctica de los Fastos, puede resolverse en los términos de una asociación de ambos en el interés por la paz, los ritos y los astros ${ }^{40}$. Dos versiones diferentes - o no tanto, si consideramos que en la sphragís de las Metamorfosis la pacificación es la condición para que la obra de Ovidio se difunda y perdure; la pax Augusta deviene pax Ovidiana:

quaque patet domitis Romana potentia terris, ore legar populi, perque omnia saecula fama (si quid habent ueri uatum praesagia) uiuam.

"y por donde se extienda el poder romano sobre las tierras dominadas, seré leído por la boca del pueblo, y a través de todos los siglos, por la fama, si hay algo de verdad en los presagios de los vates, viviré."

Dos versiones, con todo, en las que el legado monárquico, si bien diversamente, no se ha rechazado, sino asumido. Las Metamorfosis parecen afirmar poéticamente que Augusto, a diferencia de Cipo - y aun a diferencia de César - se ha atrevido a ser rex, pero - y ésta es una distinción importante especialmente resaltada en la obra -, no sólo en la tradición de Rómulo (que el hasta Romuli presagia y se continúa en las apoteosis de César y Augusto, asociadas al primus rex) ${ }^{41}$, sino en la tradición de Numa (Cipo y César no se inscriben en esta última tradición $)^{42}$. No obstante, lo que importa de la afirmación de ese legado, como hemos dicho, es que una obra poética, las Metamorfosis, se ha podido llevar a cabo. Por lo demás, otra obra poética, los Fastos, ha construido poéticamente el vínculo entre Numa y Augusto; lo ha construido de una manera que no llega a convencer fácticamente, pero sí

39 Cf. P. Martínez Astorino, "Numa y la construcción poética de la historia en las Metamorfosis de Ovidio”, QUCC, 102/131, 2012, 158-161.

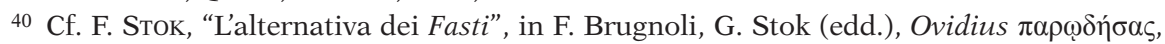
Pisa, 1992, pp. 47-73. P. Monella, "L'autorità e le sue contraddizioni: Numa nei Fasti di Ovidio", in T. Baier, M. Amerise (edd.), Die Legitimation der Einzelherrschaft im Kontext der Generationenthematik, Berlin/ New York, 2008, pp. 85-107. Con respecto a la asociación de Numa con el poeta, M. Pasco-Pranger, "A Varronian Vatic Numa? Ovid's Fasti and Plutarch's Life of Numa", in D. S. Levene, D. P. Nelis (edd.), Clio and the Poets: Augustan Poetry and the Traditions of Ancient Historiography, Leiden, 2002, pp. 291-311; más recientemente, M. GARANI, "The Figure of Numa in Ovid's Fasti”, in M. Garani, D. Konstan (edd.), The Philosophizing Muse. The Influence of Greek Philosophy on Roman Poetry, Newcastle, 2014, pp. 128-160.

41 Para la relación de Augusto con Rómulo, vid. K. GALinsKy, "La costruzione del mito augusteo: some constructions elements", in M. Labate, G. Rosati (edd.), La costruzione del mito augusteo, Heidelberg, 2013, pp. 32-33.

42 Como recordó acertadamente Andrade Marambio luego de nuestra lectura en Morón, Numa, según fuentes historiográficas (particularmente Dion. Hal. 2.60 y Liv. 1.18), fue nombrado rey por aclamación: Audito nomine Numae patres Romani (...) ad unum omnes Numae Pompilio regnum deferendum decernunt ("una vez oído el nombre de Numa, los senadores romanos, todos por unanimidad, deciden que debe ser concedido el reino a Numa Pompilio", 1.18.5). Cipo, a diferencia de Numa, previene al pueblo para que no sea posible la aclamación. Es sugestivo que el rey con representación más elogiosa en Fastos y Metamorfosis sea precisamente un anti-Cipo. 
en los términos de la poesía, como si el poeta hubiera querido decir: "ésta es la monarquía que yo quiero; probablemente no existirá, pero he dejado un testimonio poético de lo que habría podido ser"43.

Aвstract: The Cipus episode must be understood in literary terms as a mythologization of Julius Caesar previous to his apotheosis, just as the Aesculapius episode constitutes a mythologization of Augustus. The purpose is to allude in a mythologized way to two episodes of Caesar's political life: the rejection of the royal emblems first from the Senate and then from Antonius in the Lupercalia (Suet. Iul. 79.2). But, although the most central aspect of this representation of history is the device per se, it is possible to see also a reflection on monarchy in the history of Rome, which functions as a significant interpretation of the recent history: the monarchic legacy, which evokes not only Tarquinus but also Numa, should not be understood as a mistake and Cipus and Caesar, unlike Augustus, failed to assume it, even though Ovidian (Numan) conception of monarchy is problematically applied to Augustus.

KEYworDs: Cipus-Caesar; mythologization; monarchy.

43 J.-Y. Guillaumin (art. cit., p. 171) ofrece otras conclusiones sobre la reprsentación política del episodio: "En faveur de l'hypothèse d'une critique voilée envers Auguste, cependant, dont la politique est tout entière fondée sur l'augurat, force est de remarquer que l'on voit dans le livre 15 Romulus, Numa et maintenant Cipus illustrer une conception du pouvoir - la seule juste, semble-t-il, pour Ovide - d'où sont exclus tout arbitraire monarchique et toute pratique divinatoire”. Agustín Moreno se preguntó, luego de nuestra exposición, qué lugar podría tener esta visión sobre el gobierno de Augusto en el debate de la época, sugiriendo que podía ser más que una representación poética. 